\title{
Patterns of flower-visiting insects depend on flowering phenological shifts along an altitudinal gradient in subalpine moorland ecosystems
}

Natsuki Matsubara

Yokohama National University: Yokohama Kokuritsu Daigaku

Akihito Goto

Yokohama National University: Yokohama Kokuritsu Daigaku

Kei Uchida

The University of Tokyo: Tokyo Daigaku

Takehiro Sasaki ( $\square$ sasaki-takehiro-kw@ynu.ac.jp )

Yokohama National University: Yokohama Kokuritsu Daigaku

\section{Research Article}

Keywords: alpine plant, global warming, network structure, plant-pollinator network

Posted Date: November 30th, 2021

DOI: https://doi.org/10.21203/rs.3.rs-1089994/v1

License: (a) (i) This work is licensed under a Creative Commons Attribution 4.0 International License.

Read Full License 


\section{Abstract}

Alpine and subalpine moorland ecosystems contain unique plant communities, often with many endemic and threatened species, some of which depend on insect pollination. Although alpine and subalpine moorland ecosystems are vulnerable to climatic change, few studies have investigated flower-visiting insects in such ecosystems and examined the factors regulating plant-pollinator interactions along altitudinal gradients. Here, we explored how altitudinal patterns in flower visitors change according to altitudinal shifts in flowering phenology in subalpine moorland ecosystems in northern Japan. We surveyed flower-visiting insects and flowering plants at five sites differing in altitude in early July (soon after snowmelt) and mid-August (peak growing season). In July, we found a higher visiting frequency by more variable insect orders including Dipteran, Hymenopteran, Coleopteran, and Lepidopteran species at the higher altitude sites in association with the mass flowering of Geum pentapetalum and Nephrophyllidium crista-galli. In August, such altitudinal patterns were not observed, and Dipteran species dominated across the sites due to the flowering of Narthecium asiaticum and Drosera rotundifolia. Earlier snowmelt associated with recent climate change is expected to extend the growth period of moorland plants and modify flowering phenology in moorland ecosystems, leading to altered plant-pollinator interactions. Our study provides key baselines for the detection of endangered biotic interactions and extinction risks of moorland plants under ongoing climate change.

\section{Introduction}

Alpine and subalpine moorland ecosystems contain unique plant communities, often with large numbers of endemic and threatened species (Galeuchet et al. 2005; Hájková et al. 2006; Sasaki et al. 2013). Such ecosystems also provide important ecosystem services, particularly biodiversity maintenance and cultural services including recreation and aesthetic values (Tomitaka et al. 2021). Many alpine and subalpine plants depend on insects for pollination (Ollerton et al. 2011; Lefebvre et al. 2018), with approximately $78 \%$ of plant species pollinated by animals in temperate regions (Ollerton et al. 2011), forming complex, interactive plant-pollinator networks (Bascompte et al. 2003). Because the abundance and diversity of pollinators can be higher in habitats with higher flower abundance (Hegland and Boeke 2006; Hines and Hendrix 2009; Scriven et al. 2013), biodiverse mountainous moorlands are considered essential sites for insect foraging.

Alpine and subalpine moorland ecosystems are considered vulnerable to external stressors, such as climatic changes (Chapin et al. 2000; Sasaki et al. 2014; Makishima et al. 2021). Despite the ecological and conservation significance of Japan's alpine and subalpine moorland ecosystems, few studies have investigated the flower-visiting insects in these ecosystems and examined the factors regulating plantpollinator interactions along altitudinal gradients. Such understanding is essential to provide key baselines for detecting endangered plant-pollinator interactions as well as the extinction risks of moorland plants subject to ongoing climate change. 
In mountainous regions, abiotic factors such as temperature and soil conditions vary with altitude (Beniston 2006), and flowering phenology is delayed in response to drops in temperature with increasing altitude (Cornelius et al. 2013). Indeed, the same species show different flowering periods among sites with different altitudes, and clear altitudinal patterns of flowering plant species can be observed (Blionis et al. 2001). Consequently, plant-pollinator interactions are expected to change according to altitudinal shifts in flowering phenology (Zoller et al. 2002; Mizunaga and Kudo 2017; Lefebvre et al. 2018). Previous studies have generally shown that Dipteran flower visitors predominate over Hymenopteran flower visitors at higher altitudes, which can be attributed to the preference of Dipteran species for cool and moist environments compared to other flower-visiting insect orders (Chatelain et al. 2018). Moreover, Lefebvre et al. (2018) clearly demonstrated that Diptera, Coleoptera, and Hymenoptera differed significantly in the angiosperm assemblages they visited.

Here, we explored how altitudinal patterns in flower-visiting insects change according to altitudinal shifts in flowering phenology in subalpine moorland ecosystems in northern Japan. Based on the data from five sites obtained in early July (soon after snowmelt) and mid-August (peak growing season), we describe plant-pollinator interaction networks along an altitudinal gradient and during both periods of observation.

\section{Methods}

\section{Study area and moorland site characteristics}

The study area is located in the Hakkoda Mountains (peak coordinates: $40^{\circ} 41 \mathrm{~N}, 140^{\circ} 52 \mathrm{E} ; 1,584 \mathrm{~m}$ above sea level [a.s.I.]) in Aomori Prefecture, northern Japan (Fig. 1). According to the Japan Meteorological Agency, the annual maximum snow depth, mean temperature, and mean precipitation between 2009 and 2018 ranged from 3 to $6 \mathrm{~m}, 5$ to $6^{\circ} \mathrm{C}$, and 1,600 to 2,200 mm, respectively, at the Sukayu Meteorological Station $\left(40^{\circ} 38.9 \mathrm{~N}, 140^{\circ} 50.9 \mathrm{E}\right)$.

Moorlands are a form of wetland that are most often found in cool climates (Ramsar Convention Bureau, 2002). Many moorlands exist in the study area, most of which have developed in depressions in a layer of volcanic ash that settled following a huge eruption during the Pleistocene, and others are created in snow patches on gentle slopes (Muraoka and Takakura, 1988). In Japan, the development of subalpine moorlands is largely influenced by spatial patterns of snow accumulation, resulting in an interspersed distribution across the landscape.

We selected the following five moorland sites across an altitudinal gradient: (1) Tamoyachi $(1,254 \mathrm{~m}$ a.s.I.), (2) Kamikenashi (1,217 $\mathrm{m}$ a.s.I.), (3) Shimokenashi (1,047 $\mathrm{m}$ a.s.I.), (4) Takada (1,005 $\mathrm{m}$ a.s.I.), and (5) Tashiro (574 $\mathrm{m}$ a.s.l.) sites (Table 1). The moorland plant communities at these sites are dominated by Moliniopsis japonica, Eriophorum vaginatum, and Narthecium asiaticum (Sasaki et al. 2013). In all cases, taxonomic nomenclature follows the 'Plant Japanese name-Scientific name index YList YList' (BG Plants index: http://ylist.info/index.html). General descriptions of the study area and sites are provided by Sasaki et al. (2013). 
Table 1

Flower abundance (i.e., the number of inflorescence) and richness (species richness of flowering species) in early July and mid-August at five moorland sites in the Hakkoda mountain range, Aomori Prefecture, northern Japan. Data were pooled along survey transects at each site.

\begin{tabular}{|llllll|}
\hline \multirow{2}{*}{ Site } & Altitude (m above sea level) & \multicolumn{2}{c|}{ Flower abundance } & \multicolumn{2}{c|}{ Flowering plant richness } \\
\cline { 3 - 6 } & & July & August & July & August \\
\hline Tamoyachi & 1,254 & 605 & 568 & 3 & 3 \\
\hline Kamikenashi & 1,217 & 561 & 942 & 3 & 4 \\
\hline Shimokenashi & 1,047 & 389 & 123 & 5 & 4 \\
\hline Takada & 1,005 & 81 & 452 & 5 & 11 \\
\hline Tashiro & 574 & 92 & 103 & 4 & 5 \\
\hline
\end{tabular}

The studied sites are located within the special protected zone of the Towada-Hachimantai National Park, and, therefore, human disturbance such as building development, harvesting, and mining is restricted by law. Across the study sites, we observed little evidence of deer herbivory based on browsed plants and dung. Mowing and livestock grazing were not conducted at or around these sites during our sampling. Trampling into moorlands is strictly prohibited, but boardwalks are built for hiking at some sites. At these sites, our sampling transects were located far from the boardwalks to minimize potential disturbance effects. Despite these protections, habitat loss and fragmentation of these moorlands are progressing rapidly, with moorland coverage decreasing by an average of $50.01 \%$ over approximately 50 years (Makishima et al. 2021). Indeed, even when direct human impacts are minimal, earlier snowmelt in spring associated with recent climate change is facilitating the expansion of shrubby species alongside moorland habitat loss and fragmentation in Japan's mountainous regions (Kudo et al. 2017). However, the drivers of such change remain underexplored and need to be further studied based on long-term observational data.

\section{Flowering Plants}

We investigated flowering plant species in early June and mid-August in 2019 along four $2 \times 20 \mathrm{~m}$ transects (separated by at least $20 \mathrm{~m}$ ) at each site, with a total of 20 transects across all sites. Flowering abundance (i.e., the number of inflorescences) along each transect was recorded for all flowering plant species, except for wind-pollinated plant species.

To examine altitudinal shifts in flowering phenology, additional surveys were carried out at the Tamoyachi and Takada sites. For this, seven $2 \times 2 \mathrm{~m}$ plots were randomly placed within each site, and flowering abundance was recorded weekly in each plot for all flowering species from the beginning of June to the end of September 2019. 


\section{Flower-visiting Insects}

In early June and mid-August in 2019, the frequency of flower-visiting insects (i.e., the number of visits to a flower with contact with its stamens or stigma) along each transect was counted by individuals using the protocol of Pollard and Yates (1994). The observation survey was performed for 40 min per transect (20 min each in the morning and afternoon) under sunny and warm conditions. For post-hoc identification based on morphology and taxonomy at the genus or species level, we recorded pollinator visitation by taking pictures using a single-lens reflex camera (Nikon D5300) with a telephoto lens (AF-P DX NIKKOR 70-300 mm f/4.5-6.3G ED VR). As previously noted, the study sites are located within the special protected zone and, therefore, direct sampling of flower-visiting insects was not possible. We did not distinguish between individual pollinators, but counted the number of times each flower-visiting insect visited each flowering species.

\section{Data analysis}

We first generated plant and flower-visitor networks using the "bipartite" package and pooled data from the two 20-min surveys for each transect at the site level. For each sampling period (early July and midAugust), we regressed species richness and the frequency of flower-visiting insects along each transect against flower richness and abundance as well as altitude (as a surrogate for air temperature) using generalized linear mixed models (GLMMs). To account for the differences in visiting frequency sampled along each transect (Heck et al. 1975), the species richness of flower visitors was rarefied to the lowest visiting frequency for each survey. Before running the GLMMs, we checked for multicollinearity in the explanatory variables, with no variables having a variance inflation factor (VIF) score $>10$. For both species richness and visiting frequency, we ran the GLMMs with a Poisson error structure and a squareroot link function. We included the transect identity nested within site identity as a random effect in the models.

Finally, we visualized the time-series data (i.e., weekly data from the beginning of June to the end of September) of flower abundance of three dominant species in July and August at the Tamoyachi and Takada sites, namely Geum pentapetalum, Nephrophyllidium crista-galli, and N. asiaticum. All data analyses were performed using R software (version 4.0.3; R Development Core Team, 2020) using the "bipartite", "vegan", "ggplot2", and "Ime4" packages.

\section{Results}

We recorded 23 Dipteran species or species groups (i.e., spp.) from order to genus level, six Hymenopteran species or species groups from superfamily to genus level, four Coleopteran species or species groups from subfamily to genus level, and five lepidopteran species from order to genus level (Table 2). In July, we recorded higher visiting frequencies and more variable insect orders including Dipteran, Hymenopteran, Coleopteran, and Lepidopteran species, at the higher altitude sites (Kamikenashi 
and Tamoyachi; Fig. 2a). In August, such altitudinal patterns were not observed, and Dipteran species were dominant across all the sites (Fig. 2b). 
Table 2

Pollinator species identified in this study. Insects were identified based on morphology and taxonomy from order to genus level. Each species or species group is coded as "Order_ID": H, Hymenoptera; D, Diptera; C, Coleoptera; L, Lepidoptera; and O, other order.

\begin{tabular}{|c|c|c|}
\hline Species Code & Taxonomic level & Species \\
\hline D_01 & Genus & Allograpta sp. \\
\hline D_02 & Genus & Betasyrphus spp. \\
\hline D_03 & Family & Calliphoridae spp. \\
\hline D_04 & Genus & Didea spp. \\
\hline D_05 & Order & Diptera sp.1 \\
\hline D_06 & Order & Diptera sp.2 \\
\hline D_07 & Order & Diptera sp.3 \\
\hline D_08 & Order & Diptera sp.4 \\
\hline D_09 & Order & Diptera spp. \\
\hline D_10 & Family & Empididae sp.1 \\
\hline D_11 & Family & Empididae sp.2 \\
\hline D_12 & Genus & Episyrphus sp. \\
\hline D_13 & Genus & Eristalinus spp. \\
\hline D_14 & Genus & Eristalis sp. \\
\hline D_15 & Genus & Eupeodes spp. \\
\hline D_16 & Genus & Helophilus sp. \\
\hline D_17 & Tribe & Melanostomatini spp \\
\hline D_18 & Family & Mycetophilidae sp.1 \\
\hline D_19 & Genus & Parhelophilus sp. \\
\hline D_20 & Genus & Scathophaga sp. \\
\hline D_21 & Genus & Sphaerophoria spp. \\
\hline D_22 & Genus & Stomorhina sp. \\
\hline D_23 & Tribe & Syrphini spp. \\
\hline H_01 & Superfamily & Apoidea spp. \\
\hline H_02 & Genus & Bombus sp.1 \\
\hline
\end{tabular}




\begin{tabular}{|lll|}
\hline Species Code & Taxonomic level & Species \\
\hline H_03 & Genus & Bombus sp.2 \\
H_04 & Genus & Bombus spp. \\
H_05 & Order & Hymenoptera sp. \\
H_06 & Order & Hymenoptera spp. \\
C_01 & Genus & Cephaloon sp. \\
\hline C_02 & Genus & Dasytes spp. \\
\hline C_03 & Subfamily & Donaciinae spp. \\
\hline C_04 & Genus & Oedemeronia sp. \\
\hline L_01 & Genus & Colias sp. \\
\hline L_02 & Genus & Fabriciana sp. \\
\hline L_03 & Order & Lepidoptera spp. \\
\hline L_04 & Family & Lycaenidae spp. \\
\hline L_05 & Genus & Thoressa sp. \\
\hline O_01 & Family & Acrididae sp.1 \\
\hline O_02 & Family & Acrididae sp.2 \\
\hline O_03 & Family & Acrididae sp.3 \\
\hline O_04 & Family & Acrididae sp.4 \\
\hline O_05 & Order & Araneae spp. \\
\hline O_06 & Genus & Cicadella sp \\
\hline O_07 & Order & Hemiptera spp. \\
\hline O_08 & Genus & Pantala sp. \\
\hline O_09 & Family & Salticidae sp. \\
\hline O_10 & Tettigoniidae spp. \\
\hline
\end{tabular}

In July, G. pentapetalum, N. crista-galli, Schizocodon soldanelloides, N. asiaticum, and Pogonia japonica were the dominant flowering plants, with rarer species including Aletris foliata, Ixeridium dentatum subsp. ozense, and Menziesia multiflora (Fig. 3a). The abundance of G. pentapetalum was highest at the higheraltitude sites (Tamoyachi and Kamikenashi), while N. crista-galli was most abundant at the middlealtitude sites (Shimokenashi and Takada). N. asiaticum was only observed in flower at the Tashiro site. 
In August, $N$. asiaticum and Drosera rotundifolia were the dominant flowering plants along with Parnassia palustris, Sanguisorba tenuifolia var. alba, Platanthera tipuloides subsp. nipponica, Spiranthes sinensis var. amoena, Inula ciliaris, and Hosta sieboldii var. rectifolia (Fig. 3b). Flowering individuals of $N$. asiaticum were commonly found across all sites in August.

The structure of plant and flower-visitor networks at each site in July and August are shown in Fig. 4 (also see Tables 2 and 3). We observed more diverse plant-pollinator interactions in July than in August. For example, in July, across all sites except for Tashiro, G. pentapetalum, N. crista-galli, and S. soldanelloides were linked with diverse orders including Hymenoptera, Diptera, Coleoptera, and Lepidoptera (Fig. 4a). The Tashiro site lacked these flowering species, and flower visitors were dominated by Dipteran species. In August, $N$. asiaticum was the dominant flowering plant species across all the sites, and this species was linked primarily with Dipteran species (Fig. 4b). 
Table 3

All 21 flowering plant species identified in this study. Each species is coded as "F_ID". Six flowering plant species without F_ID were not visited by pollinators during our observations.

\begin{tabular}{|ll|}
\hline ID & Species \\
\hline F_01 & Nephrophyllidium crista-galli \\
\hline F_02 & Schizocodon soldanelloides \\
\hline F_03 & Geum pentapetalum \\
\hline F_04 & Narthecium asiaticum \\
\hline F_05 & Drosera rotundifolia \\
\hline F_06 & Platanthera tipuloides subsp. nipponica \\
\hline F_07 & Menziesia multiflora \\
\hline F_08 & Aletris foliata \\
\hline F_09 & Parnassia palustris \\
\hline F_10 & Hosta sieboldii var. rectifolia \\
\hline F_11 & Sanguisorba tenuifolia var. alba \\
\hline F_12 & Spiranthes sinensis var. amoena \\
\hline F_13 & Inula ciliaris \\
\hline F_14 & Ixeridium dentatum subsp. ozense \\
\hline F_15 & Pogonia japonica \\
\hline & Gaultheria adenothrix \\
\hline & Trientalis europaea \\
\hline & Vaccinium oxycoccos \\
\hline & Peucedanum multivittatum \\
\hline
\end{tabular}

In July, there were significant positive relationships between the visiting frequency of pollinators and flower abundance, and between visiting frequency and altitude (Table 4). In August, there were significant positive relationships between insect visiting frequency and flower abundance, and between visiting frequency and flowering species richness (Table 4). In both July and August, there were no significant relationships between pollinator species richness and the explanatory variables (Table 4). 
Table 4

Results of generalized linear mixed models (GLMMs) regressing species richness and frequency of flower-visiting insects along each survey transect against flower richness and abundance, and altitude. Transect identity nested within site was included as a random effect in the models. Significant regression coefficients are in bold. $(P<0.05)$.

\begin{tabular}{|llllll|}
\hline Response variables & Variables & Coefficient & SE & Z-value & P value \\
\hline Visiting frequency in July & (Intercept) & 1.235 & 0.923 & 1.338 & 0.181 \\
\hline & Flower abundance & 0.009 & 0.002 & 4.222 & 0.000 \\
\hline & Flower richness & -0.042 & 0.199 & -0.210 & 0.834 \\
\hline Pollinator richness in July & Altitude & 0.002 & 0.001 & 2.410 & 0.016 \\
\hline & (Intercept) & 0.879 & 0.573 & 1.533 & 0.125 \\
\hline & Flower richness & 0.089 & 0.104 & 0.853 & 0.393 \\
\hline Visiting frequency in August & Flower abundance & 0.000 & 0.001 & 0.173 & 0.863 \\
\hline & Altitude & 0.000 & 0.001 & 0.639 & 0.523 \\
\hline & Flowercept) abundance & 0.008 & 0.003 & 2.690 & 0.007 \\
\hline & Flower richness & 0.380 & 0.142 & 2.677 & 0.007 \\
\hline & Altitude & -0.000 & 0.001 & -0.333 & 0.739 \\
\hline Pollinator richness in August & (Intercept) & 0.994 & 0.477 & 2.085 & 0.037 \\
\hline & Flower abundance & 0.000 & 0.001 & 0.117 & 0.907 \\
\hline & Flower richness & 0.004 & 0.049 & 0.084 & 0.933 \\
\hline & Altitude & 0.000 & 0.000 & 0.117 & 0.907 \\
\hline
\end{tabular}

Time-series data of flower abundance for the three dominant species (G. pentapetalum, N. crista-galli, and $N$. asiaticum) at the Takada (1,005 $\mathrm{m}$ a.s.l.) and Tashiro (1,254 $\mathrm{m}$ a.s.I.) sites are shown in Fig. 5. Notably, the flowering phenology of $G$. pentapetalum clearly differed between these sites along with $N$. crista-galli and $N$. asiaticum, although there was some overlap.

\section{Discussion}

Our observations identified altitudinal patterns in insect flower visitors according to altitudinal variations in flowering phenology in the subalpine moorland ecosystems of northern Japan. In early July, we observed higher visiting frequencies by more variable insect orders including Dipteran, Hymenopteran, Coleopteran, and Lepidopteran species at higher altitudes than at the lower altitude sites. This is attributed to the mass flowering of $G$. pentapetalum and $N$. crista-galli at these higher-altitude sites. In 
mid-August, such altitudinal patterns were not observed, and Dipteran species dominated across all the sites in association with the flowering of $N$. asiaticum and $D$. rotundifolia.

In both July and August, we observed a positive relationship between the visiting frequencies of pollinators and flower abundance (Table 4), possibly because pollinators search and select locations with high flower abundance to increase the efficiency of resource acquisition (Hegland and Boeke 2006). This also explains the positive relationship between flower-visiting frequency and altitude in July (Table 4), when flower abundance increased with altitude (Fig. 3a). In August, we observed the highest species richness (Table 1; Fig. 3b) and frequency of flower visitors (Fig. 2b; Table 4) at Takada. Compared to the other sites, Takada is surrounded by wider stretches of moorland and is located nearer to neighboring moorlands (Fig. 1). Therefore, it is likely that favorable foraging conditions (i.e., greater accessibility to nectar resources) enhanced the frequency of pollinator visits at this site. In contrast, in July, both the abundance and richness of flowering plants were low at Takada (Fig. 3a; Table 1) with correspondingly low pollinator visitor frequencies.

The plant-pollinator networks (Fig. 4) suggest that G. pentapetalum, N. crista-galli, and S. soldanelloides flower mainly in early summer, soon after snowmelt, and attract diverse insect orders. In comparison, $N$. asiaticum mainly flowered during the peak growing season and primarily attracted Diptera. In particular, given that Hymenopteran species have a greater preference for flowering plants than Dipteran species (Branquart and Hemptinne 2000; Mizunaga and Kudo 2017), our results suggest a greater preference for G. pentapetalum, N. crista-galli, and S. soldanelloides by Hymenopteran species over other species in these moorland ecosystems. In contrast, many Dipteran species are generalists (Classen et al. 2020; Zhao et al. 2021), with phenological shifts across time (i.e., between early July and mid-August) and space (i.e., with altitude) having less of an effect on their flower-visiting frequency.

Many previous studies have suggested that Diptera predominates over other insect orders, such as Hymenoptera, Coleoptera, and Lepidoptera, at high altitudes and, therefore, its species play primary roles in plant-pollinator interactions (Zoller et al. 2002; Mizunaga and Kudo 2017; Lefebvre et al. 2018). Consequently, turnover between insect orders along altitudinal gradients can often be observed (Lefebvre et al. 2018). In our study, we did not observe a clear turnover between insect orders along the altitudinal gradient (Figs. 2 and 4). This might be attributed to altitudinal shifts in flowering phenology, whereby the observed patterns of flower-visiting insects reflect the degree of altitudinal differentiation in flowering time (Fig. 5). Notably, in August, the flowering period of the main flowering species, N. asiaticum, overlapped between the Tamoyachi and Takada sites (Fig. 5), with flowering individuals commonly found across all sites (Fig. 3). This likely explains the predominance of Diptera across these sites in August. Additionally, as our altitudinal gradient was less stratified than in the case of studies in higher mountainous areas, such as the European Alps (e.g., Lefebvre et al. 2018; ranging from 1,000 to 2,700 a.s.l.), environmental limitations on the spatial distributions of insect flower visitors could be weaker. The relatively cool summer temperatures across the Hakkoda sites (ranging $17.34-20.41^{\circ} \mathrm{C}$ between July and September) would have also favored Dipteran species. Based on all of these observations, we suggest that altitudinal patterns in flower-visiting insects reflect phenological variations in flowering. 
Despite the ecological and conservation significance of Japan's alpine and subalpine moorland ecosystems, little is known about flower-visiting insects in these ecosystems and the factors regulating plant-pollinator interactions along altitudinal gradients. Most concerningly, habitat loss and fragmentation of these moorlands are progressing rapidly in association with climatic warming and associated environmental changes (Makishima et al. 2021). In particular, earlier snowmelt associated with recent warming is likely linked to longer moorland plant growing periods and altered flowering phenology, leading to changes in plant-pollinator interactions. Importantly, our study provides key baseline data for the detection of endangered biotic interactions and extinction risks in moorland plant communities subject to ongoing climate change.

\section{Declarations}

\section{Conflicts of interest}

None.

\section{Funding}

This work was financially supported by a Fostering Joint International Research A award (no. 19KK0393) and a Grant-in-Aid for Scientific Research B (No.18H02221 and No. 20H04380) from the Japanese Ministry of Education, Culture, Sports, Science and Technology.

\section{Authors' contributions}

NM and TS conceived and designed the study; All authors collected the data; NM analyzed the data; NM and TS wrote the first draft of the manuscript; All the authors contributed to manuscript revisions and approved the final version.

\section{Acknowledgements}

We thank our laboratory members for helping with the fieldwork, especially Daichi Makishima, Shoko Uchihara, and Mahoro Tomitaka. We also thank Taiki Tachibana and Yuki Iwachido for their valuable suggestions for data analysis.

\section{Availability of data and material}

The data supporting the result in the paper will be archived in Dryad at the time of acceptance and the data DOI will be included. 


\section{References}

1. Bascompte J, Jordano P, Melián CJ, Olesen JM (2003) The nested assembly of plant-animal mutualistic networks. Proc Natl Acad Sci USA 100:9383-9387

2. Beniston M (2006) Mountain weather and climate: A general overview and a focus on climatic change in the Alps. Hydrobiologia 562:3-16

3. Blionis GJ, Halley JM, Vokou D (2001) Flowering phenology of Campanula on Mt Olympos. Greece Ecography 24:696-706

4. Branquart E, Hemptinne J-L (2000) Selectivity in the exploitation of floral resources by hoverflies (Diptera: Syrphinae). Ecography 23:732-742

5. Chapin FS, Mcguire AD, Randerson J et al (2000) Arctic and boreal ecosystems of western North America as components of the climate system. Glob Change Biol 6:211-223

6. Chatelain P, Plant A, Soulier-Perkins A, Daugeron C (2018) Diversity increases with elevation: empidine dance flies (Diptera, Empididae) challenge a predominant pattern. Biotropica 50:633-640

7. Classen A, Eardley CD, Hemp A et al (2020) Specialization of plant-pollinator interactions increases with temperature at Mt.Kilimanjaro. Ecology and Evolution2182-2195. doi: 10.1002/ece3.6056

8. Cornelius C, Estrella N, Franz H, Menzel A (2013) Linking altitudinal gradients and temperature responses of plant phenology in the Bavarian Alps. Plant Biol 15:57-69

9. Galeuchet DJ, Perret C, Fischer M (2005) Performance of Lychnis flos-cuculi from fragmented populations under experimental biotic interactions. Ecology 86:1002-1011

10. Heck KL, van Belle G, Simberloff D (1975) Explicit calculation of the rarefaction diversity measurement and the determination of sufficient sample size. Ecology 56:1459-1461

11. Hegland SJ, Boeke L (2006) Relationships between the density and diversity of floral resources and flower visitor activity in a temperate grassland community. Ecol Entomol 31:532-538

12. Hines HM, Hendrix SD (2009) Bumble Bee (Hymenoptera: Apidae) Diversity and Abundance in Tallgrass Prairie Patches: Effects of Local and Landscape Floral Resources. Environ Entomol 34:1477-1484

13. Hájková P, Hájek M, Apostolova I (2006) Diversity of wetland vegetation in the Bulgarian high mountains, main gradients and context-dependence of the $\mathrm{pH}$ role. Plant Ecol 184:111-130

14. Kudo G, Kawai Y, Amagai Y, Winkler DE (2017) Degradation and recovery of an alpine plant community: experimental removal of an encroaching dwarf bamboo. Alpine Botany 127:75-83

15. Lefebvre V, Villemant C, Fontaine C, Daugeron C (2018) Altitudinal, temporal and trophic partitioning of flower-visitors in Alpine communities. Sci Rep 8:1-12

16. Makishima D, Sutou R, Goto A et al (2021) Potential extinction debt due to habitat loss and fragmentation in subalpine moorland ecosystems. Plant Ecol 222:445-457

17. Mizunaga Y, Kudo G (2017) A linkage between flowering phenology and fruit-set success of alpine plant communities with reference to the seasonality and pollination effectiveness of bees and flies. 
Oecologia 185:453-464

18. Muraoka H, Takakura S (1988) Explanatory text of the geological map of the Hakkoda Geothermal area.. Miscellaneous Map Series (Geological Survey of Japan, Tsukuba, 27 p pp 21-24

19. Ollerton J, Winfree R, Tarrant S (2011) How many flowering plants are pollinated by animals? Oikos 120:321-326

20. Pollard E, Yates TJ (1993) Monitoring Butterflies for Ecology and Conservation. Chapman \& Hall, London

21. R Development Core Team (2020) R: A language and environment for statistical computing (ver. 4.0.3). R Foundation for Statistical Computing, Vienna

22. Ramsar Convention Bureau (2002) What Is the Ramsar Convention on Wetlands? Ramsar Information Paper no. 2. Ramsar Convention Bureau, Gland.

https://www.ramsar.org/sites/default/files/documents/library/info2007-02-e.pdf. Accessed 8 Jan 2020

23. Sasaki T, Katabuchi M, Kamiyama C et al (2013) Variations in species composition of moorland plant communities along environmental gradients within a subalpine zone in northern japan. Wetlands 33:269-277

24. Sasaki T, Katabuchi M, Kamiyama C et al (2014) Vulnerability of moorland plant communities to environmental change: Consequences of realistic species loss on functional diversity. J Appl Ecol 51:299-308

25. Scriven LA, Sweet MJ, Port GR (2013) Flower density is more important than habitat type for increasing flower visiting insect diversity.International Journal of Ecology. doi:

$10.1155 / 2013 / 237457$

26. Tomitaka M, Uchihara S, Goto A, Sasaki T (2021) Species richness and flower color diversity determine aesthetic preferences of natural-park and urban-park visitors for plant communities. Environmental and Sustainability Indicators 11:100130

27. Zhao Y, Lázaro A, Li H et al (2021) Morphological trait-matching in plant-Hymenoptera and plantDiptera mutualisms across an elevational gradient. Journal of Animal Ecology 1-14. doi: 10.1111/1365-2656.13614

28. Zoller H, Lenzin H, Erhardt A (2002) Pollination and breeding system of Eritrichium nanum (Boraginaceae). Plant Syst Evol 233:1-14

\section{Figures}




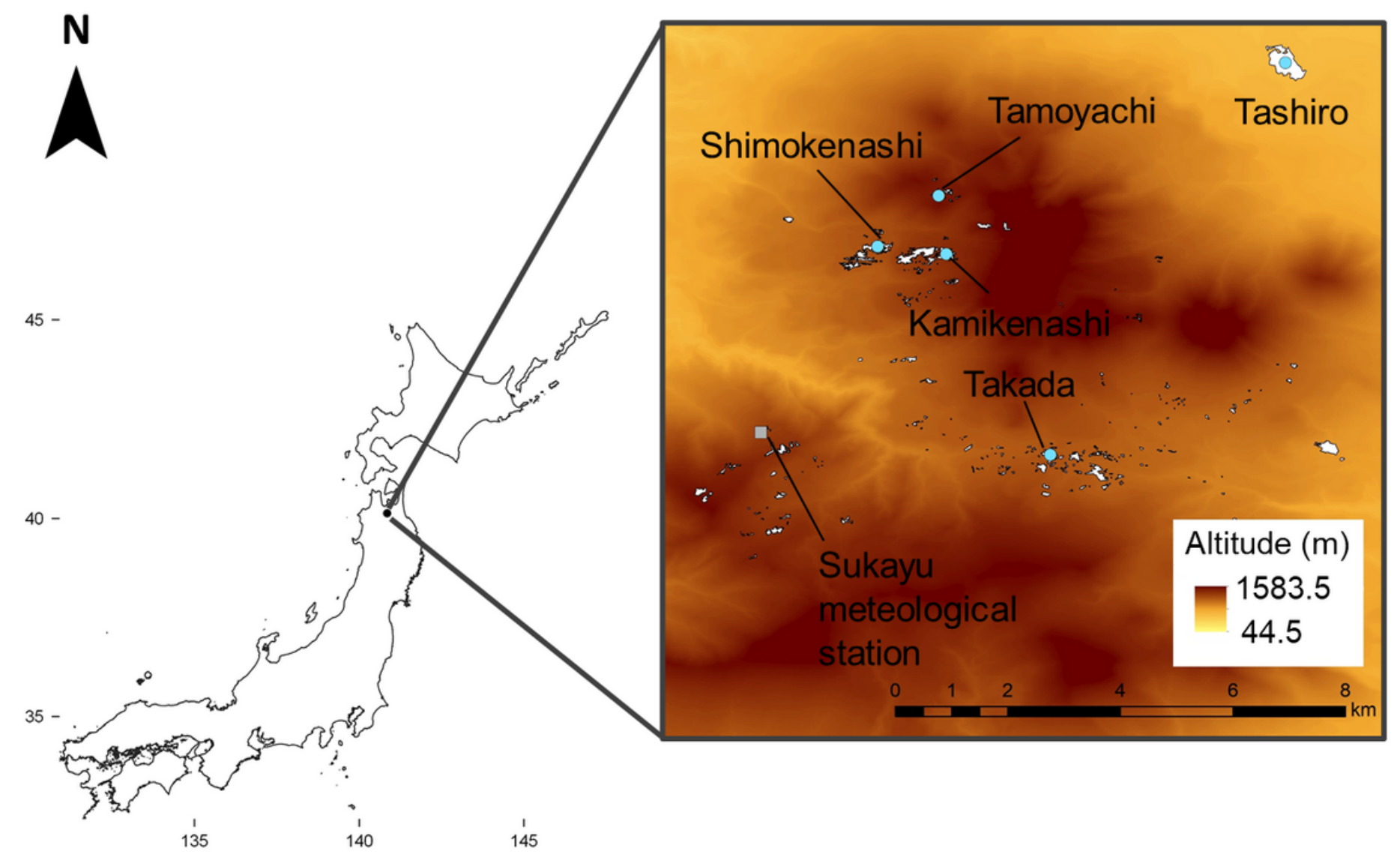

\section{Figure 1}

Map showing the locations of the five moorland sites in the Hakkoda Mountains, Aomori Prefecture, northern Japan. Circles represent the studied moorlands and the square represents Sukayu Meteorological Station. All moorlands $(n=365)$ within the Hakkoda mountain range are delineated by black lines
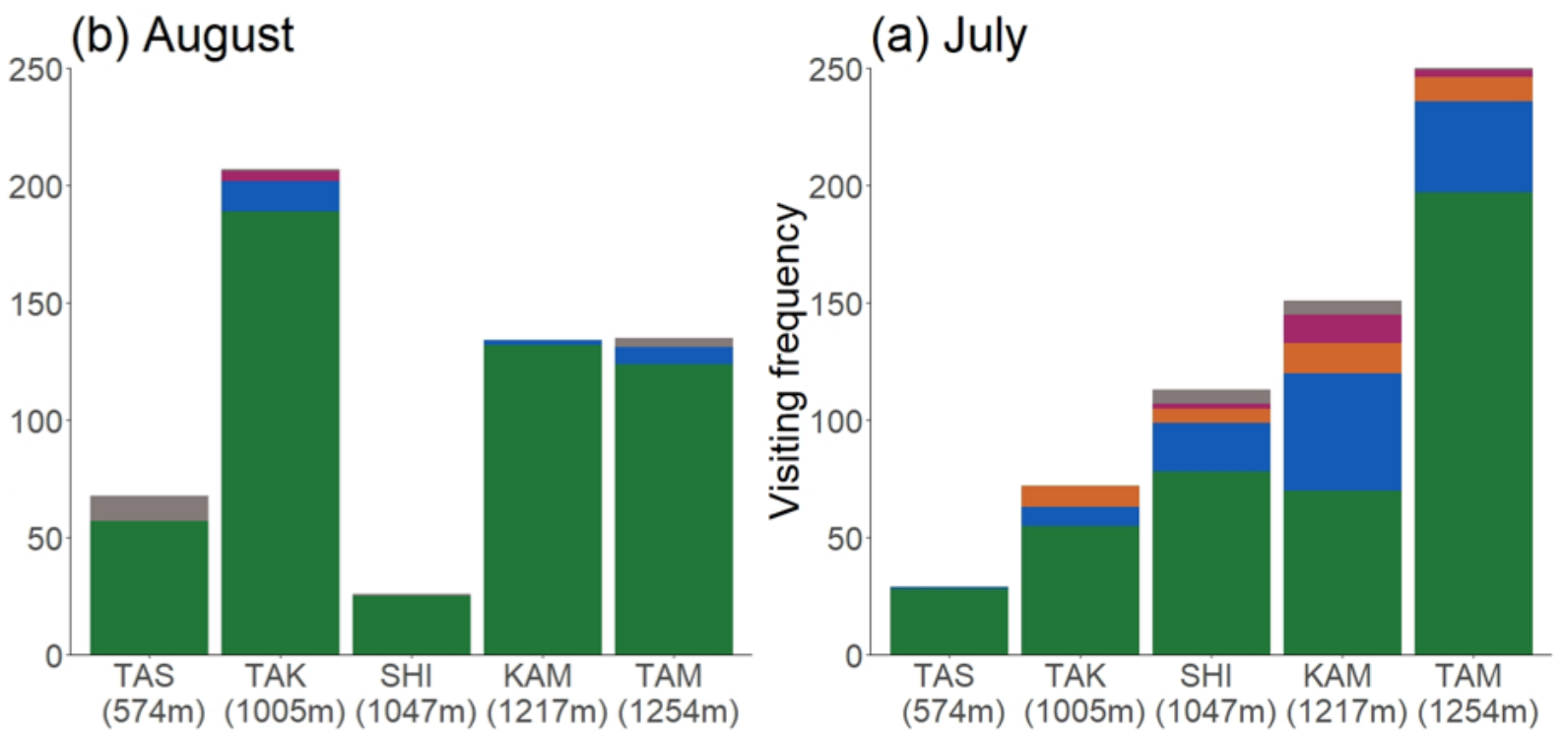

Order

Other Lepidoptera Coleoptera Hymenoptera Diptera

Fig. 2. 
Frequency of flower visitors by insect orders in early July and mid-August at each site: TAM, Tamoyachi; SHI, Shimokenashi; KAM, Kamikenashi; TAK, Takada; and TAS, Tashiro

\section{(a) July}

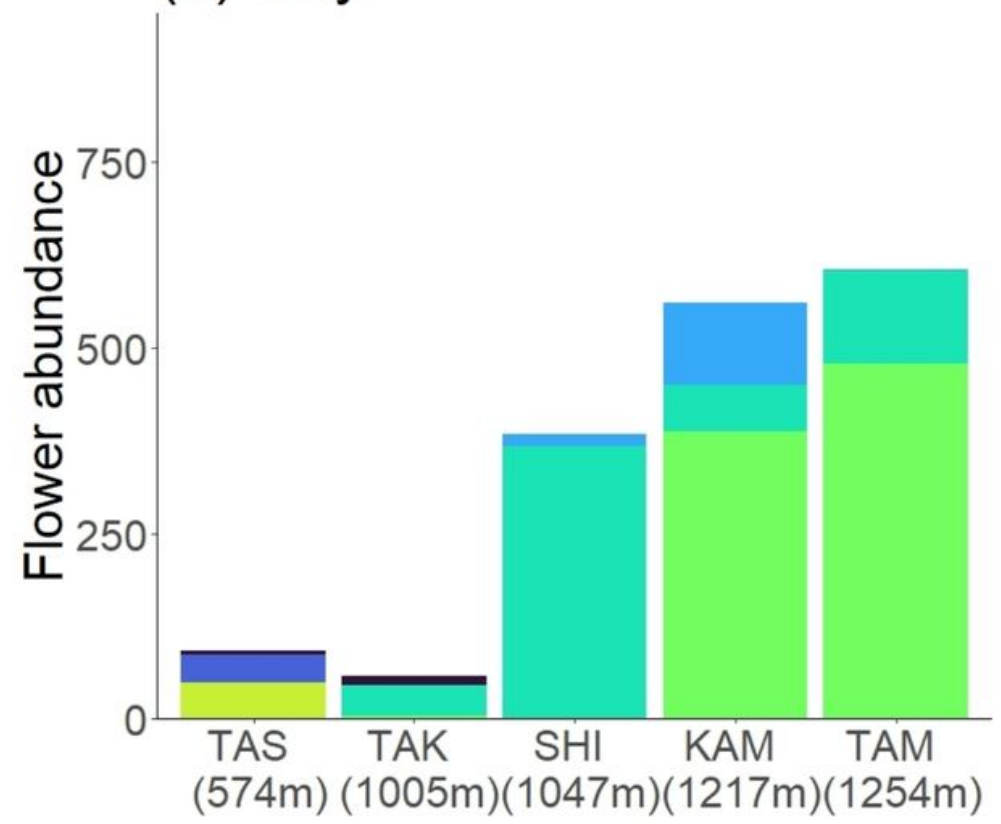

(b) August

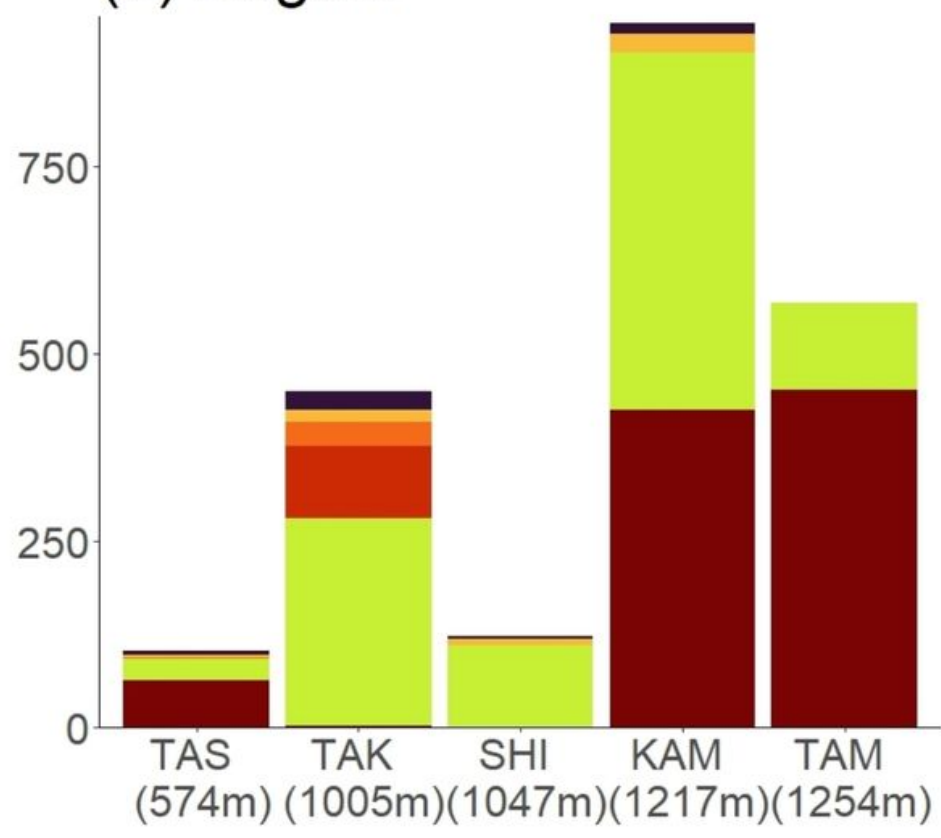

Figure 3

Abundance of common flowering plants in early July and mid-August at each site: TAM, Tamoyachi; SHI, Shimokenashi; KAM, Kamikenashi; TAK, Takada; and TAS, Tashiro
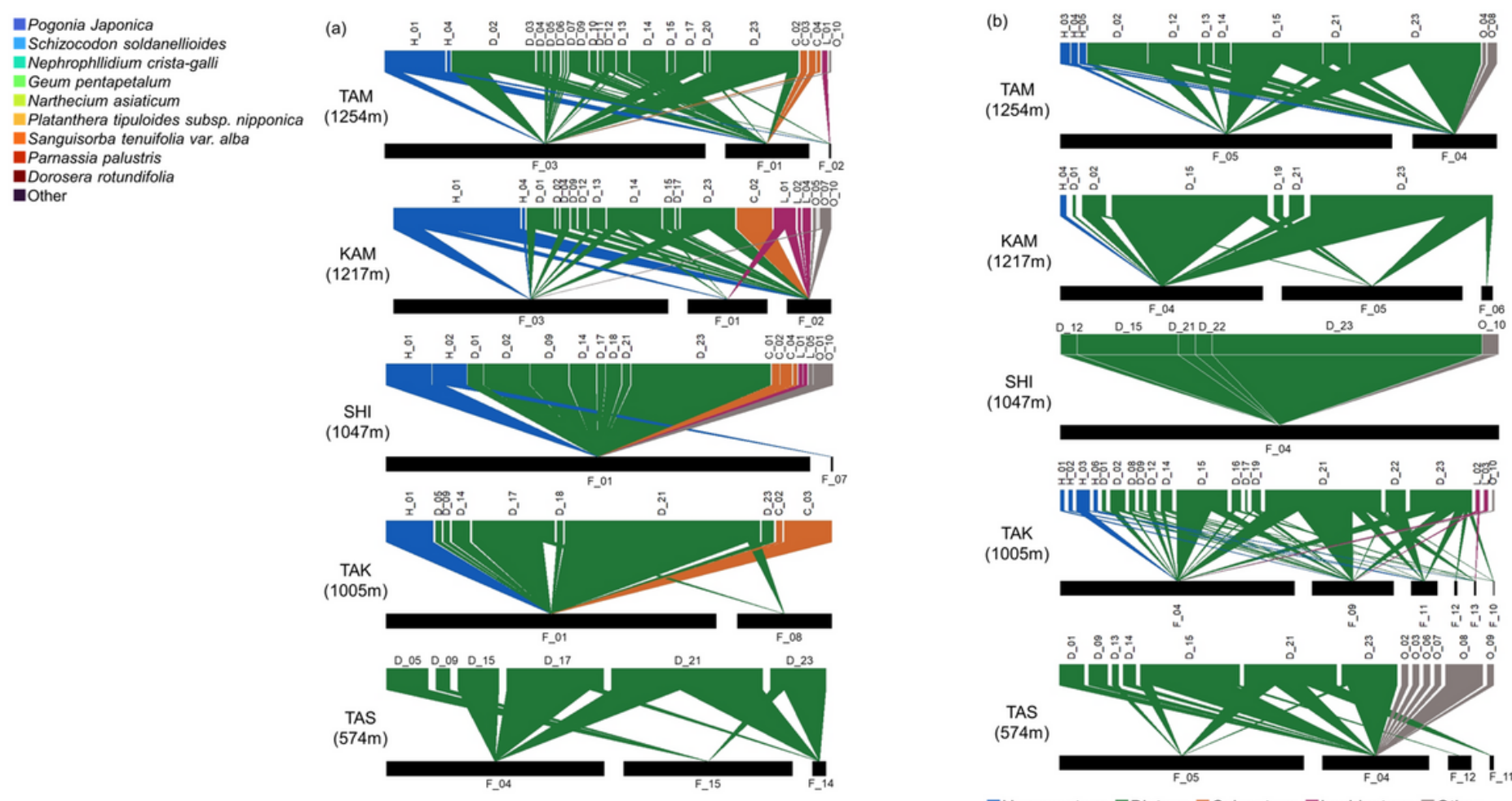

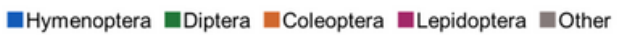


Plant-pollinator networks in early July and mid-August at each site. The width of the upper bars represents the visiting frequency of each species or species group (see Table 2), and the width of the lower bars represents the abundance of each flowering plant species (see Table 3)

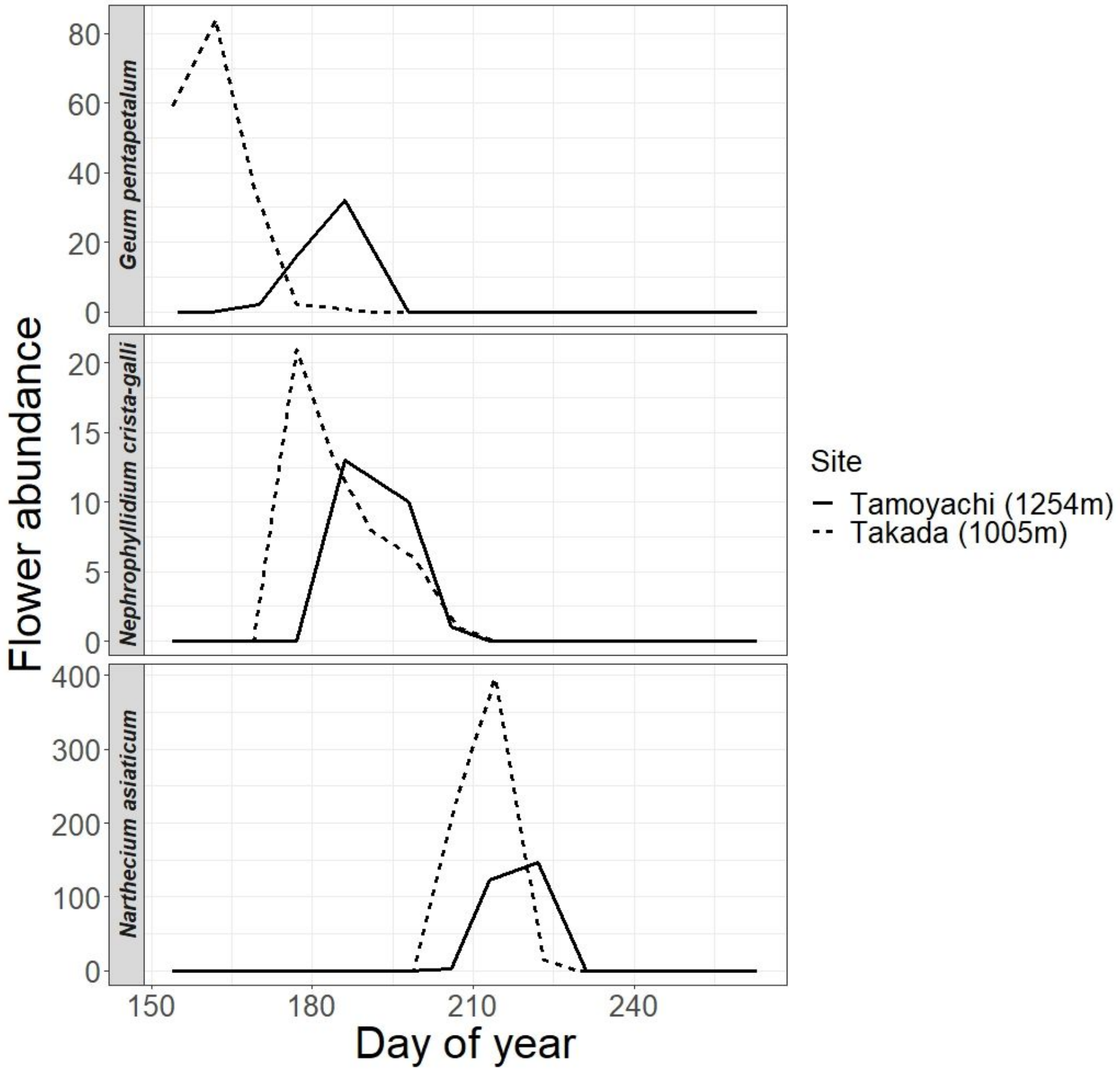

Figure 5

Time-series plot of flower abundance for three dominant species (G. pentapetalum, N. crista-galli, and N. asiaticum) at Takada (1,005 $\mathrm{m}$ above sea level [a.s.I.]) and Tashiro (1,254 $\mathrm{m}$ a.s.I.). Flower abundance is plotted against the days of year 